\title{
PENGARUH MUSIC MOVEMENT THERAPY TERHADAP KEMAMPUAN AKTIVITAS HARIAN PADA PASIEN STROKE
}

\author{
Andreas Rantepadang ${ }^{1}$, Angelia Tendean ${ }^{2}$ \\ Fakultas Keperawatan, Universitas Klabat \\ E-mail: rantepadang@unklab.ac.id, angelia.tendean@unklab.ac.id
}

\begin{abstract}
Stroke is a condition of death of brain structure caused by circulatory disorders in the brain which results in weakness and decreases daily activity ability of stroke patients. Music movement therapy (MMT) is a complementary action to increase the activity of stroke patients. Purpose: The purpose of this study is to identify the effect of music movement therapy (MMT) on the ability of daily activities of stroke patients. Method: Quasi-experiment pretest and posttest nonequivalent control group method. Determination of the sample using consecutive sampling technique, 48 respondents were given standard hospital handling and MMT 5 times a week (30 minutes each therapy) for two weeks, while the 16 respondents ware only given hospital standard treatment without MMT. Results: The results showed average that the patient's daily activity ability before the intervention was 26.87 very dependent and increased after intervention to 67.52 moderately dependence, in the control group on the first day 26.56 and after fourteen increased to 49.68 but remained in the highly dependent category. The Wilcoxon test and Mann-Whitney showed the effect of MMT on the daily activity ability of stroke patients ( $p$-value 0.000). Recommendation: This study recommends the use of MMT as a basis for consideration for alternative therapies in improving the ability of daily activities of stroke patients.
\end{abstract}

Keywords: Therapy, ability, activity, stroke

\begin{abstract}
ABSTRAK
Stroke merupakan suatu kondisi kematian jaringan otak yang disebabkan oleh gangguan peredaran darah di otak yang mengakibatkan kelemahan serta penurunan kemampuan aktivitas harian penderita stroke. Music movement therapy (MMT) merupakan tindakan komplementer untuk meningkatkan aktivitas pasien stroke. Tujuan: penelitian ini bertujuan untuk menganalisa pengaruh music movement therapy terhadap kemampuan aktivitas harian pasien stroke. Metode: Metode penelitian menggunakan quasi experiment pretest and posttest nonequivalent control group. Penentuan sampel menggunakan teknik consecutive sampling, 48 responden diberikan standar penanganan rumah sakit dan MMT 5 kali seminggu (masingmasing 30 menit terapi) selama dua minggu, sedangkan 16 responden hanya diberikan standar rumah sakit tanpa MMT. Hasil: Hasil penelitian menunjukkan bahwa rata-rata kemampuan aktivitas harian pasien sebelum intervensi 26.87 kategori sangat tergantung dan setelah intervensi meningkat menjadi 67.52 kategori tergantung sedang, pada kelompok kontrol pada pertama 26.56 dan setelah hari ke empat belas meningkat menjadi 49.68 tetapi tetap pada kategori sangat tergantung. Uji Wilcoxon dan Mann-whitney menunjukkan pengaruh yang signifikan MMT terhadap kemampuan aktivitas harian pasien stroke dengan p-value <.05. Rekomendasi: MMT dapat digunakan sebagai terapi komplementer untuk meningkatkan kemampuan aktivitas harian pasien stroke.
\end{abstract}

Kata kunci: Terapi, kemampuan, aktivitas, stroke 


\section{Pendahuluan}

Stroke merupakan suatu kondisi dimana tubuh mengalami gangguan sirkulasi pada otak yang bisa mengakibatkan kelumpuhan bahkan kematian (Purwanto, 2016). Lebih jelasnya Sommer (2013) menjelaskan stroke juga dikenal sebagai Cerebrovaskular Accident (CVA) atau serangan otak yang disebabkan oleh adanya iskemia, perdarahan, serangan otak, atau emboli.

Stroke telah menjadi masalah yang serius di dunia. Tiap tahun prevalensi stroke semakin meningkat, tahun 2013 penderita stroke di dunia mencapai 25.7 juta jiwa, dimana 6.5 juta penderita stroke meninggal dunia dan 113 juta penderitanya mengalami kecacatan (Donkor, 2018). Lebih lanjut lagi Center of Disease Control and Prevention (2017) menjelaskan bahwa stroke membunuh sekitar 140.000 orang Amerika setiap tahun, artinya 1 dari 20 orang yang meninggal disebabkan oleh Stroke.Berdasarkan data Riset Kesehatan Dasar (2018) penderita stroke di Indonesia mengalami peningkatan dari tahun $20137 \%$ menjadi 10\% di tahun 2018, dimana Sulawesi utara menempati ranking ke empat penderita stroke terbanyak.

Menurut Jhonson, Onuma, Owolabi, dan Sachdev (2016) stroke menempati urutan ketiga penyebab kecacatan di dunia. Penyebab kecacatan atau penurunan fungsi motorik tergantung lokasi dan jumlah jaringan otak yang terpengaruh. Stroke akan menyebabkan aliran darah ke otak tidak dapat mencapai wilayah yang mengontrol fungsi tubuh, sehingga bagian tubuh itu tidak akan berfungsi sebagaimana mestinya (Ignatavicius \& Workman, 2015). Lebih lanjut Paciaroni, Agnelli, Caso dan Bogousslavsky (2012) menjelaskan $75 \%$ penderita stroke akan mengalami penurunan fungsi motorik diantaranya kelemahan tangan, kaki dan juga pinggul yang akan mempengaruhi aktivitas keseharian pasien seperti makan, minim, ganti baju, defekasi, dan juga pergerakkan (Roger,et.al, 2014).

Penanganan yang tepat dapat menurunkan resiko kecacatan akibat stroke. Rehabilitasi merupakan penanganan yang tepat untuk menangani pasien dengan penurunan fungsi

Published by Faculty of Nursing | Universitas Klabat motorik untuk meningkatkan aktivitas harian pasien (Staines, Mccoy \& Brooks, 2009). Music movement therapy merupakan kombinasi terapi musik dengan latihan Range of Motion (ROM) yang bermanfaat untuk meningkatkan fungsi motorik (Tong, et.al, 2015, Jun, Young \& Kim, 2012).

Perawat memegang peranan penting terhadap keberhasilan rehabilitasi pasien stroke. Berdasarkan teori keperawatan Handerson perawat memiliki peran dalam memenuhi kebutuhan dasar manusia diantaranya membantu aktivitas harian pasien. Lebih lanjut teori Orem menjelaskan keberhasilan perawatan pasien dapat terpenuhi dengan kemampuan individu untuk terlibat dalam proses perawatan diri (self-care) dan peran perawat untuk membantu self-care pasien (Aini, 2018)

Melalui proses rehabilitasi music movement therapy kemampuan aktivitas harian pasien stroke dapat meningkat sehingga tingkat kemandirian dan kualitas hidup merekapun secara secara berangsur meningkat. Adapun tujuan dari penelitian ini adalah untuk menganalisa pengaruh Music Movement Therapy terhadap kemampuan aktivitas harian penderita stroke.

\section{Bahan dan Metode Penelitian}

Rancangan penelitian dalam penelitian ini menggunakan metode eksperimen semu dengan pendekatan Pretest and posttest nonequivalent control group, dimana suatu penelitian yang menguji coba suatu intervensi pada sekelompok subjek disertai kelompok kontrol sebagai pembanding (Putri, 2018)

Populasi dalam penelitian ini adalah semua pasien stroke yang dirawat di salah satu rumah sakit pemerintah di Sulawesi Utara, Teknik pengambilan sampel dalam penelitian ini adalah consecutive sampling, dimana semua subjek penelitian yang datang dan memenuhi kriteria inklusi pada waktu yang telah ditentukan (Reichardt, 2019). Kriteria inklusi penelitian (1) Pasien yang terdiagnosa stroke iskemik dan hemoragi oleh dokter melalui pemeriksaan diagnostik (CT scan, MRI), (2) Berusia 18 tahun ke atas, (3) Kesadaran kompos mentis (CM), (4) GCS 15, (5) Tanda-tanda vital (pernapasan, 
tekanan darah, nadi, suhu) pasien stabil dalam waktu 2x24 jam, (6) Bersedia menjadi responden selama dua minggu; sedangkan untuk kriteria eksklusi (1) Gangguan pendengaran, (2) Memiliki fraktur pada ekstremitas, (3) Memiliki nyeri sendi, (4) Kekuatan otot 0 (5) Peningkatan tekanan intrakranial (Sakit kepala, mual muntah, penglihatan ganda dan tekanan darah meningkat). Penderita stroke yang dirawat pada bulan JuniJuli berjumlah 84 pasien yang memenuhi kriteria inklusi adalah 64 responden dimana 48 responden untuk kelompok intervensi dan 16 responden untuk kelompok kontrol cara pembagian kelompok kontrol dibagi berdasarkan ruang perawatan.

Pengumpulan data dilakukan setelah peneliti mendapat surat lulus uji etik dari komite etik tempat peneliti melakukan penelitian (055/ECKEPK/IV/2019). Responden yang telah memenuhi kriteria inklusi penelitian diberikan Informed consent bila bersedia menjadi responden penelitian maka dilakukan pengukuran Pre-test pada hari pertama sebelum intervensi, pengukuran kemampuan aktivitas harian pasien dengan menggunakan kuesioner barthel index, yang terdiri 10 indikator yaitu makan, mandi, perawatan diri, berpakaian, buang air kecil, buang air besar, penggunaan toilet, transfer, mobilitas, naik turun tangga (Kowalak, 2009). Peneliti yang menilai langsung dan memberikan skoring sesuai dengan keadaan pada pasien dimana (0: tidak mampu, 5: dibantu, 10 Mandiri) total nilai yang paling rendah adalah 0 dan yang paling tinggi adalah 100 sedangkan interprestasinya adalah 0-20 ketergantungan penuh, 21-61 Ketergantungan berat/sangat tergantung, 62-90 ketergantungan sedang, 91-99 ketergantungan ringan dan 100 pasienya mandiri.

Intervensi Music Movement Therapy dilakukan selama 60 menit setiap hari, 5x/minggu selama 2 minggu, terapi ini terdiri dari tiga tahap yaitu: tahap persiapan aktivitas, tahap aktivitas dan tahap akhir aktivitas. Tahap persiapan peneliti mempersiapkan peralatan seperti speker, music instrument, mempersiapkan suasana rungan yang tenang serta mempersiapkan pasien dengan memberikan pendidikan kesehatan tantang proses rehabilitasi dan tujuan music movement therapy serta mengajarkan range of motion aktif, waktu yang diperlukan adalah 20 menit. Tahap melakukan aktivitas, pasien

Published by Faculty of Nursing | Universitas Klabat melakukan ROM exercise yang terdiri dari 21 gerakan aktif dan pasif sambil diiringi musik klasik Mozart (Beethoven-Moonlight Sonata, symphony) lama melakukan aktivitas ini adalah 30 menit. Tahapan akhir pasien mengungkapkan kesulitan dan keuntungan setelah melakukan music movement therapy, lama tahap akhir ini adalah 10 menit (Rantepadang \& Tendean, 2019; Young, \& Kim, 2012) pada kelompok kontrol dilakukan pengukuran barthel index dan mendapat perawatan standar rumah sakit saja tanpa MMT, tapi setelah penelitian kelompok kontrol diberikan tindakan (MMT) yang sama untuk menjaga prisip keadilan dalam penelitian.

Post-test dilakukan setelah intervensi music movement therapy pada hari terahir (Hari ke 14). Post-test dilakukan seperti pada pre-test yaitu pengukuran Kemampuan aktivitas harian responden pada kelompok intervensi maupun kontrol. Setelah itu melakukan analisis data yang terbagi dalam beberapa tahap, yaitu preanalysis phase, preliminary assessment, preliminary action, principal analysis, interpretive phase (Polit \& Beck, 2012).

\section{Hasil Penelitian}

Tabel 1 Rata-Rata Kemampuan Aktivitas

Harian Pasien

\begin{tabular}{llll}
\hline Kelompok & $\begin{array}{l}\text { Pre } \\
\text { (Hari 1) }\end{array}$ & $\begin{array}{l}\text { Post } \\
\text { (Hari } \\
\text { Ke14) }\end{array}$ & $\begin{array}{l}\text { P-Value uji } \\
\text { Wilcoxon dan } \\
\text { Mann-whitney }\end{array}$ \\
\hline Intervensi & $\mathbf{2 6 . 8 7}$ & 67.54 & 0.000 \\
Kontrol & 26.56 & 49.68 & \\
\hline
\end{tabular}

Dari 64 responden yang terlibat dalam penelitian mayoritas berjenis kelamin laki-laki 41 (64\%) responden dan $23(36 \%)$ berjenis kelamin perempuan. Berdasarkan table 1 Rata-rata kemampuan aktivitas harian sebelum intervensi berada pada 26.87 kategori ketergantunan berat/sangat tergantung dan mengalami peningkatan setelah intervensi menjadi 67.52 kategori ketergantungan sedang, pada kelompok kontrol hari pertama 26.56 meningkat menjadi 49.68 setelah hari ke empat belas, tetapi tetap berada pada kategori sangat tergantung. Pada Uji Wilcoxon maupun Mann-Whitney diketahui bahwa ada pengaruh signifikan music movement therapy terhadap kemampuan aktivitas harian pasien stroke dengan nilai $\mathrm{p}=0,000<0.05$. 


\section{Pembahasan}

Mayoritas responden adalah laki-laki sebanyak 41 responden (64\%). Data ini mengidentifikasikan bahwa laki-laki mempunyai jumlah yang lebih besar dalam menderita stroke dibandingkan perempuan. Hasil ini sesuai dengan penelitian yang dilakukan oleh Afridi, Ali, Ahmad, \& Alam, (2015) terhadap 100 pasien stroke di Pakistan yang menunjukkan bahwa jumlah penderita stroke laki-laki lebih besar (68\%) bila dibandingkan dengan perempuan (32\%). Studi ini dipertegas dengan studi yang dilakukan oleh Handayani (2012) yang menyatakan bahwa insiden stroke pada perempuan lebih rendah $(31,1 \%)$ bila dibandingkan dengan laki-laki $(68,9 \%)$.

Wanita biasanya mendapat serangan stroke yang lebih rendah daripada laki-laki, berhubungan dengan hormon seksual wanita yaitu estrogen yang membantu terjadinya vasodilator pembuluh darah (Masood, Roach, Beauregard, et al, 2010). Serta memiliki peranan dalam proteksi terhadap penyakit pembuluh darah atau pencegahan dalam proses terjadinya arterosklerosis dengan efek menurunkan kadar Low Density Lipoprotein (Handayani 2012).

Rata-rata aktivitas harian responden sebelum intervensi berada pada ketergantunan berat sesudah intervensi mengalami peningkatan menjadi ketergantungan sedang, pada kelompok kontrol tetap berada pada ketergantungan berat. Ini mengidentifikasikan bahwa responden mengalami peningkatan aktivitas harian setelah mengikuti program music movement therapy, sama halnya pada hasil uji statistik bivariate, dimana kemampuan aktivitas harian sebelum dan sesudah intervensi music movement therapy, maupun di dapatkan nilai $\mathrm{p}=0.000(<0.05)$ ini menunjukkan bahwa secara statistik ada peningkatan kemampuan aktivitas harian yang signifikan sesudah intervensi music movement therapy, begitu juga bila dibandingkan antara kelompok intervensi dan kontrol $(\mathrm{p}=0.000)$, dengan kata lain bahwa ada pengaruh music movement therapy terhadap kemampuan aktivitas harian pasien stroke walaupun pada kelompok kontrol ada peningkatan rata-rata kemampuan aktivitas harian tetapi secara kategori tidak mengalami perubahan.

Published by Faculty of Nursing | Universitas Klabat
Hasil ini sejalan dengan Acton (2013) yang menyatakan bahwa Music movement therapy yang merupakan gabungan dari musik dan range of motion mampu meningkatkan kekuatan otot. Musik yang didengar melalui korteks auditori akan menstimulasi impuls saraf motorik yang dikenal dengan RAS (Reticular activiting system). Pengaruh fungsi fisik ini didasarkan atas interaksi antara pendengaran dan system penggerak atau suara dan pergerakan (Murrock \& Higgins, 2009). Rangsangan melalui neuromuskuler akan meningkatkkan rangsangan pada serat syaraf otot ekstremitas terutama syaraf parasimpatis yang merangsang untuk produksi asetilcholin, sehingga mengakibatkan kontraksi. Mekanisme melalui muskulus terutama otot polos ekstremitas dapat meningkatkan metabolisme pada metakonderia untuk menghasilkan ATP yang dimanfaatkan oleh otot polos ekstremitas sebagai energi untuk kontraksi (Arthur \& Guyton, 2007; Reese, 2013). Peningkatan kekuatan otot pasien mempengaruhi peningkatan kemampuan perawatan diri seperti mandi, sikat gigi, ganti baju dan toileting.

Orem menekankan bahwa Perawat berperan meningkatkan kemampuan aktivitas pasien stroke dalam pemenuhan kebutuhan dirinya. Perawatan diri pasien bukan hanya menjadi tanggung jawab perawat, tetapi menjadi tanggung jawab pasien. Perawat berperan sebagai fasilitator dalam memandirikan pasien stroke yang mengalami defisit perawatan diri supaya pasien dapat menggunakan dirinya seoptimal mungkin dalam usaha perawatan dirinya.

\section{Kesimpulan dan Saran}

Ada peningkatan kemampuan aktivitas harian pasien stroke setelah diberikan MMT selama 14 hari dan berdasarkan uji statistik diketahui bahwa ada pengaruh music movement therapy terhadap kemampuan aktivitas harian pasien stroke.

Penelitian ini diharapkan dapat digunakan sebagai dasar pertimbangan terapi komplementer bagi pasien yang menderita stroke terutama yang mengalami penurunan kemampuan aktivitas harian dan diperlukannya pengembang penelitian lanjut dengan menggunakan teknik pengambilan sampel secara random dan jumlah yang sama antara intervensi dan kontrol. 


\section{Daftar Pustaka}

Acton, A. (2013). Issues in nursing . Atlanta: Sholarly Edition .

Afridi, R., Ali, Z., Ahmad, A., \& Alam, I. (2015). Age and Gender Specific Stroke Risk Factors in a Teaching Hospital In Khyber Pakhtunkhwa. Journal Postgraduate Medical Institute, 76-82.

Aini, N.(2018). Teori Model keperawatan. Malang: Universitas Muhamadiyah Malang

Center of disease control and perevention. (2017). Stroke facts. diakses tgl 05 November 2019 dari https://www.cdc.gov/dhdsp/data_statisti cs/fact_sheets/fs_stroke.htm

Handayani, F. (2012). Angka Kejadian Serangan Stroke Pada Wanita Lebih Rendah dari Pada Laki-laki. Journal Unimus, 17-21.

Ignatavicius, D., \& Workman, L. (2015). Medical Surgical Nursing Patient Centered Collaborative Care. Missouri: Elsevier Health .

Jhonson, W., Onuma, O., Owolabi, M., dan Sachdev, S. (2016). Stroke: a global response is needed.Bulletin of the World Health Organization 2016; 94: 634634A.

doi:http://dx.doi.org/10.2471/BLT.16.18 1636

Kowalak, J. (2009). Lippincott's nursing procedures. Philadelphia : Wolters Kluwer.

Masoon D, Roach, Beauregard K. (2010). Impact of sex hormone metabolism on the cascular effect of monopausal hormone therapy in cardiocascular disease. Current Drug Metabolism. 11 (8): 693 714

Murrock, C., \& Higgins, P. (2009). The theory of music, mood, and movement to improve

Published by Faculty of Nursing | Universitas Klabat health outcomes. Journal of Advanced Nursing, 2249-2257.

Paciaroni, M., Agnelli, G., Caso, V dan Bogousslavsky, J. (2012). Manifestation of stroke.Germany: Karger

Polit \& Beck, (2012). Nursing Research. Generating and assesing evidance for nursing practice. Lippincott William and Wilkins, Ninth Edition.

Purwanto, H. (2016). Modul bahan ajar cetak keperawatan: bahan ajar medikal bedah II. PUSDIK SDM Kesehatan

Putri, D. (2018). Pengantar riset keperawatan. Yogyakarta: Pustaka Baru Press

Rantepadang, A. \& Tendean, A. (2019) Pengaruh music movement therapy terhadap kemampuan aktivitas harian pada pasien stroke di RSUP. Prof. DR. R.D Kandou Manado. Jurnal Skolastik Keperawatan.30-38

Reese, N. (2013). Muscle and Sensory Testing. Missouri: Elsevier health Sciences.

Reichardt, C. (2019). Quasi experimentation a guide to design and analysis. New York: The Guilford Press.

Roger, V., Go, A., Mozaffarian, D., Bejamin, E., Berry, J., \& Blaha, M. (2014). Hear Disease and Stroke Statistics. A report from the American Heart Association Circulation, 1-268.

Riset Kesehatan Dasar (Riskesdas) 2018. Data Statistik Penderita Stroke di Indonesia. Jakarta

Staines, R, Mccoy, WE dan Brooks, D. (2009). Functional impairments following stroke: implications for rehabilitation. Curr Issues Cardiac Rehab Prevent. 17(1):5-8.

Tong, Y, Forreider, B, Sun, X, Geng, X, Zhang, W, Du, W, Zhang, T \& Ding, Y. (2015) 
Music-supported therapy (MST) in improving post-stroke patients' upperlimb motor function: a randomised controlled pilot study, Neurological Research, 37:5, 434-440, DOI: 10.1179/1743132815Y.0000000034

Young, R., \& Kim, M. (2012). The efect of music movement therapy on physical and psychological states of stroke patients. Journal of clinical nursing, 22-31. 